\title{
TENDÊNCIAS GENÉTICAS PARA CARACTERÍSTICAS DE CRESCIMENTO EM REBANHOS NELORE CRIADOS NA REGIÃO DO TRÓPICO ÚMIDO DO BRASIL
}

\author{
Thaymisson SANTOS DE LIRA ${ }^{1}$, LeONARdo De SOUSA PEREIRA ${ }^{1}$, FERNANDO BRITO LOPES ${ }^{2}$, JORGE \\ LUIS FERREIRA ${ }^{3}$, RAYSILDO BARBOSA LÔBO ${ }^{4}$, GENEÍlDES CRISTINA DE JESUS SANTOS ${ }^{1}$ \\ ${ }^{1}$ Mestrandos do Programa de pós-graduação da Universidade Federal do Tocantins, Araguaína, TO, Brasil \\ ${ }^{2}$ Bolsista Pesquisador da EMBRAPA/CERRADOS, Brasília, DF, Brasil \\ ${ }^{3}$ Professor Doutor da Universidade Federal do Tocantins, Araguaína, TO, Brasil - jlferreira@uft.edu.br \\ ${ }^{4}$ Professor Doutor da Universidade de São Paulo, Ribeirão Preto, SP, Brasil.
}

\begin{abstract}
Foram estimados (co)variâncias, coeficientes de herdabilidade e tendências genéticas, bem como preditas mudanças genéticas para peso aos 120 (P120), 210 (P210), 365 (P365), 450 (P450) e 550 (P550) dias de idade em animais da raça Nelore criados na região do Trópico Úmido do Brasil. Foram utilizados 65.876 registros de animais nascidos entre os anos de 1993 a 2010, criados a pasto. Os componentes de (co)variância foram estimados pelo método da máxima verossimilhança restrita e os valores genéticos foram preditos por modelos mistos sob modelo animal. As tendências genéticas foram estimadas pela regressão dos valores genéticos sobre o

herdabilidade do efeito direto estimados foram de $0,37 \pm 0,019 ; \quad 0,39 \pm 0,019 ; \quad 0,41 \pm 0,013 ; \quad 0,41 \pm 0,015 \quad$ e $0,41 \pm 0,021$ para P120, P210, P365, P450 e P550, respectivamente. As estimativas de herdabilidades maternais para P120 e P210 foram 0,05 $\pm 0,011$ e $0,06 \pm 0,011$, respectivamente. Os ganhos genéticos diretos médios foram 1,326, 2,014, 2,670, 3,056 e 3,128 kg/ano para P120, P210, P365, P450 e P550, respectivamente. As estimativas dos parâmetros e tendência genética indicam a existência de progresso genético para pesos pré e pósdesmame, nos rebanhos da região do Trópico Úmido do Brasil.
\end{abstract} ano de nascimento dos animais. Os coeficientes de

PALAVRAS-CHAVE: (co)variâncias; ganho genético; herdabilidades; melhoramento genético animal; peso pósdesmama; peso pré-desmama.

\section{GENETIC TRENDS FOR GROWTH TRAITS IN NELLORE CATTLE RAISED IN THE HUMID TROPICAL REGION OF BRAZIL}

\begin{abstract}
(Co)variances, heritability and genetics change were estimated for weight at 120 (W120), 210 (W210), 365 (W365), 450 (W450) and 550 (W550) days of age in Nellore cattle from the Humid Tropical region of Brazil. A total of 65,876 records of animals born between 1993 to 2010 and raised on pasture were used. The (co)variance components were estimated by restricted maximum likelihood, and breeding values were predicted using an individual animal model. The genetic trends were plotted by linear regression of breeding values in the animals'

birth year. The heritability coefficients due to direct genetic effect were $0.37 \pm 0.019 ; 0.39 \pm 0.019 ; 0.41 \pm 0.013$; $0.41 \pm 0.015$ and $0.41 \pm 0.021$ The maternal heritability estimates for W120 and W210 were $0.05 \pm 0.011$ and $0.06 \pm 0.011$, respectively. The genetic gains were 1.326 , $2.014,2.670,3.056$ and $3.128 \mathrm{~kg} /$ year for W120, W210, W365, W450 and W550, respectively. The estimates of genetic parameters and trends indicate the existence of genetic progress in pre- and post-weight traits from herds of Brazil Tropic Humid region.
\end{abstract}

KEYWORDS: animal breeding program; (co)variances; genetic gain; heritability; post-weaning weight; preweaning weight. 


\section{INTRODUÇÃO}

No Brasil, a região do Trópico Úmido praticamente se confunde com a Amazônia Legal, representada pelos estados do Acre, Amapá, Amazonas, Mato Grosso, Pará, Rondônia, Roraima, Tocantins e parte do Maranhão (oeste do Meridiano $44^{\circ}$ ), correspondendo a aproximadamente $61 \%$ do território brasileiro $\left(5,2\right.$ milhões de $\left.\mathrm{km}^{2}\right)$. Nos últimos anos, a atividade pecuária nessa região vem se expandindo, em termos de evolução do rebanho bovino, sendo que grande parte desse crescimento está relacionado à migração de produtores de outras regiões do país, bem como à adoção de práticas de manejo, recuperação de pastagens, utilização de tecnologias e conscientização da preservação ambiental (DIAS-FILHO, 2011).

Segundo dados do Instituto Brasileiro de Geografia e Estatística (IBGE), no período 1997/2007, houve um aumento de $78 \%$ do efetivo bovino nos municípios que compõem a região do Trópico Úmido (IBGE, 2007; 2010). Entretanto, o grande desafio para a produção animal a pasto nessa fronteira agrícola brasileira seria o aumento da eficiência por meio do uso de tecnologias mais intensivas, tanto em relação ao manejo e recuperação de pastagens, quanto ao desempenho produtivo e reprodutivo desses rebanhos.

Uma das mais importantes decisões do pecuarista moderno que pretende maximizar sua produção é a seleção visando ao melhoramento genético animal. Um bom indicador da resposta à seleção ou ao progresso genético a ser alcançado é o conhecimento das estimativas de parâmetros genéticos para características ponderais na raça em estudo (GONÇALVES et al., 2011).

O conhecimento do desempenho fenotípico e genético de uma população tem importância na realização de ajustes necessários ao processo seletivo, isto é, na avaliação dos critérios estabelecidos no processo de seleção, bem como nos resultados dos programas de melhoramento genético aplicados. Por meio do conhecimento de parâmetros genéticos e de estimativas de mudança genética é possível realizar o acompanhamento e estabelecimento de diretrizes que guiem os programas de melhoramento genético, apreciando o ganho genético ao longo do tempo para que os resultados sirvam de elementos orientadores de ações futuras (SANTOS et al., 2012).

Alguns pesquisadores discutiram parâmetros e tendências genéticas nas regiões Nordeste, Norte, Centro-oeste, Sul e Sudeste (PIMENTA FILHO et al., 2001; MALHADO et al., 2002; PLASE et al.,
2002; GUSMÃO et al., 2009; GONÇALVES et al., 2011; LAUREANO et al., 2011) e, mais recentemente, SANTOS et al., (2012) na região Norte do Brasil. Entretanto, pesquisas efetivas na região do Trópico Úmido do Brasil, o qual contempla estados também da região Nordeste e Centro-Oeste, avaliando o progresso genético e fenotípico de bovinos Nelore criados a pasto, são incipientes.

Dessa forma, objetivou-se estimar (co)variâncias e parâmetros genéticos e predizer as tendências genéticas e fenotípicas para pesos padronizados aos 120, 210, 365, 450 e 550 dias de idade em bovinos da raça Nelore criados na região do Trópico Úmido do Brasil, manejados a pasto.

\section{MATERIAL E MÉTODOS}

Foram utilizadas informações referentes a animais da raça Nelore, nascidos entre os anos de 1993 e 2010, criados em rebanhos localizados nos Estados do Maranhão (MA), Mato Grosso (MT), Pará (PA), Rondônia (RO) e Tocantins (TO), participantes do Programa de Melhoramento Genético da Raça Nelore, da Associação Nacional de Criadores e Pesquisadores (PMGRN-ANCP).

As características estudadas foram pesos padronizados aos 120, 210, 365, 450 e 550 dias de idade (P120, P210, P365, P450 e P550), utilizados como critérios de seleção no PMGRN (Lôbo et al., 1998). Os dados iniciais incluíram 65.876 registros de animais nascidos entre 1993 a 2010, criados a pasto. Todas as estatísticas descritivas e testes de comparação entre as médias fenotípicas, ou seja, entre os pesos ajustados às idades-padrão descritas acima, foram realizados por meio dos procedimentos MEANS e GLM e as médias comparadas por meio do teste de comparação múltipla de Tukey (SAS, 2002).

Foram realizadas análises de variância utilizando-se o procedimento GLM (SAS, 2002) para verificar a importância de fontes de variação não genéticas sobre as características em estudo. Consideraram-se os efeitos fixos de sexo e grupos de contemporâneos (GC), formados por meio da concatenação (SAS, 2002) de fatores não genéticos que afetaram significativamente $(p<0,001)$ as características em estudo como, rebanho, ano e estação de nascimento do animal (janeiro a abril $=1$; maio a agosto $=2$; e setembro a dezembro $=3$ ). Para as características de pesos pré-desmama (P120 e P210) utilizou-se como covariável a idade da vaca ao parto.

O número de animais, touros, vacas, grupos 
de contemporâneos e as médias, desvios-padrão, coeficientes de variação para pesos padronizados aos

$120,210,365,450$ e 550 dias de idade estão apresentados na Tabela 1.

Tabela 1. Número de animais, média, desvio padrão e coeficiente de variação das características analisadas em rebanhos Nelore criados no Trópico Úmido do Brasil.

\begin{tabular}{lccccccc}
\hline Carácter & $\begin{array}{c}\mathrm{N}^{\mathbf{o}} \mathrm{de} \\
\text { animais }\end{array}$ & $\begin{array}{c}\mathrm{N}^{\mathrm{o}} \text { de } \\
\text { Touros }\end{array}$ & $\begin{array}{c}\mathrm{N}^{\mathbf{o}} \text { de } \\
\text { Vacas }\end{array}$ & $\mathrm{N}^{\mathbf{o}}$ de GC & Média $(\mathrm{kg})$ & DP $(\mathrm{kg})$ & $\mathrm{CV}(\%)$ \\
\hline P120 & 52.726 & 671 & 24.569 & 329 & 127,51 & 16,90 & 13,25 \\
P210 & 53.518 & 706 & 25.118 & 484 & 184,76 & 24,61 & 13,32 \\
P365 & 49.305 & 773 & 25.388 & 408 & 231,37 & 32,52 & 14,05 \\
P450 & 42.561 & 733 & 22.276 & 367 & 267,05 & 38,28 & 14,33 \\
P550 & 23.646 & 455 & 13.441 & 261 & 314,79 & 48,28 & 15,34 \\
\hline
\end{tabular}

P120= Peso ajustado aos 120 dias de idade; P210= Peso ajustado aos 210 dias de idade; P365= Peso ajustado aos 365 dias de idade; $\mathrm{P} 450=$ Peso ajustado aos 450 dias de idade; P550= Peso ajustado aos 550 dias de idade; $\mathrm{N}^{\circ}=$ número; GC $=$ Grupo de contemporâneos; $\mathrm{DP}=$ desvio-padrão; $\mathrm{CV}=$ coeficiente de variação.

As análises unicaráter dos pesos prédesmame (P120 e P210) foram realizadas segundo o modelo descrito em (I), enquanto que para P365, P450 e P550 o modelo é descrito em (II).

$$
y=X \beta+Z_{1} a+Z_{2} m+Z_{3} p+e
$$

em que: $y=$ vetor de observações (P120 e P210); $\beta=$ vetor dos efeitos fixos (grupo de contemporâneos e ordem de parto); $a=$ vetor do efeito genético aditivo direto; $m=$ vetor do efeito genético aditivo maternal; $p=$ vetor do efeito de ambiente permanente maternal; $X=$ matriz de incidência que associa $\beta$ com $y ; Z_{1}, Z_{2}$ e $Z_{3}=$ matrizes de incidência dos efeitos genéticos direto, maternal e de ambiente permanente maternal, respectivamente; e $e=$ vetor dos efeitos residuais.

$$
y=X \beta+Z a+e
$$

em que: $y=$ vetor de observações (P365, P450 e $\mathrm{P} 550$ ); $\beta=$ vetor dos efeitos fixos (grupo de contemporâneos e ordem de parto); $a=$ vetor do efeito genético aditivo direto; $X=$ matriz de incidência que associa $\beta$ com $y ; Z=$ matriz de incidência do efeitos genético direto; e, $e=$ vetor dos resíduos.

Nas análises com o modelo completo, as distribuições e matriz de (co)variâncias foram definidas como:

$$
\begin{gathered}
E[d]=E[m]=E[p]=E[e]=0, \\
E[y \mid d, m, p]=X \beta+Z_{1} d+Z_{2} m+Z_{3} p \\
{\left[\begin{array}{l}
\mathrm{d} \\
\mathrm{m} \\
\mathrm{p} \\
\mathrm{e}
\end{array}\right]=\left[\begin{array}{cccc}
\mathrm{A} \sigma_{\mathrm{d}}^{2} & \mathrm{~A} \sigma_{\mathrm{dm}} & 0 & 0 \\
\mathrm{~A} \sigma_{\mathrm{dm}} & \mathrm{A} \sigma_{\mathrm{m}}^{2} & 0 & 0 \\
0 & 0 & \mathrm{I}_{\mathrm{d}} \sigma_{p}^{2} & 0 \\
0 & 0 & 0 & \mathrm{I}_{\mathrm{N}} \sigma_{e}^{2}
\end{array}\right]}
\end{gathered}
$$

Em que:

$\sigma_{\mathrm{d}}^{2}=$ variância genética aditiva direta;

$\sigma_{\mathrm{m}}^{2}=$ variância genética aditiva maternal;

$\sigma_{\mathrm{dm}}=$ covariância genética aditiva entre os efeitos direto e maternal;

$A=$ matriz de parentesco entre os animais;

$\sigma_{p}^{2}=$ variância do ambiente permanente maternal;

$\sigma_{e}^{2}=$ variância residual;

$I_{d}, I_{N}=$ matrizes identidade de ordens apropriadas, com d= número de vacas (mães dos animais com dados) e

$\mathrm{N}=$ número total de animais com dados.

As estimativas de (co)variâncias foram obtidas pelo método da Máxima Verossimilhança Restrita Livre de Derivadas - DFREML, utilizandose o aplicativo MTDFREML (BOLDMAN et al., 1995). Para avaliar as tendências genéticas e fenotípicas, utilizou-se a regressão das médias anuais dos valores genéticos (aditivo e maternal) e dos pesos sobre o ano de nascimento do animal.

Para ilustrar e predizer o ganho genético baseado nos componentes de variância e parâmetros genéticos, realizou-se simulação do ganho genético por meio da seguinte fórmula:

$$
\Delta G=\frac{i \times h^{2} \times \sigma_{a}}{L},
$$

em que é $\Delta G$ o ganho genético, $i$ é a intensidade de seleção $(1,28$, como retenção de $10 \%$ de machos e $50 \%$ de fêmeas), $h^{2}$ é a herdabilidade devido ao efeito genético aditivo direto, $\sigma_{p}$ é o desvio-padrão (FALCONER, 1996) e $L$ é o intervalo médio de geração (PEREIRA, 1999). Para determinação de $L$, simulou-se a seleção baseada na utilização de touros durante cinco anos (entre dois e seis anos) e fêmeas durante sete anos (entre três e nove anos), o que resultou em $L=5$ anos. Dessa forma, o ganho genético $(\Delta G)$ pode ser dado em $\mathrm{kg} / \mathrm{ano}$. 


\section{RESULTADOS E DISCUSSÃO}

As médias para peso padronizado aos 120 dias (P120) e peso aos 210 dias (P210) foram de $127,51 \pm 16,90 \quad \mathrm{~kg} \quad$ e $184,76 \pm 24,61 \mathrm{~kg}$, respectivamente. Para peso aos 205 dias de idade, HOLANDA et al. (2004), na região Nordeste do Brasil, encontraram média de 157,55 $( \pm 22,80) \mathrm{kg}$ e BOCCHI et al. (2004), estudando rebanhos bovinos Nelore de diferentes regiões do Brasil, obtiveram médias de pesos aos 205 dias de 163,15 $( \pm 27,78) \mathrm{kg}$ na região Centro-oeste, $154,23( \pm 29,43) \mathrm{kg}$ na região Nordeste, $165,45( \pm 28,87) \mathrm{kg}$ na região Sul e 165,45 $( \pm 28,08) \mathrm{kg}$ na região Sudeste. Ao desmame, observou-se que os pesos dos animais foram superiores aos relatados nas demais regiões do Brasil, o que pode ser justificado por manejos, objetivos e critérios de seleção diferentes, entre outros.

De maneira geral, os pesos médios na região do Trópico Úmido do Brasil estão num estrato intermediário aos descritos em outras regiões do país, sendo semelhantes aos reportados por MERCADANTE et al. (2003), BERTAZZO et al. (2004), MALHADO et al. (2005), BOLLIGON et al. (2008), LAUREANO et al. (2011), e SANTOS et al. (2012).

No entanto, quando se observam as médias fenotípicas dos pesos entre as unidades federativas (Tabela 2), verifica-se que, para uma mesma idade padrão, existe alta variabilidade nos pesos, sugerindo que fatores genéticos e ambientais atuam de formas diferentes entre os estados que compõem a região do Trópico Úmido. Dessa forma, pode-se deduzir que o delineamento dos programas de melhoramento genético, com seus objetivos e critérios, nessas regiões, vêm sendo conduzidos de forma diferenciada entre as unidades federativas, ou seja, é possível que sejam utilizados critérios de seleção diferentes entre os Estados.

Tabela 2. Pesos médios e desvio padrão das características P120, P210, P365, P450 e P550 dias de idade, segundo a distribuição pelos Estados de maior representatividade no Trópico Úmido do Brasil.

\begin{tabular}{lccccc}
\hline Estado & P120 & P210 & P365 & P450 & P550 \\
\hline MA & $121,63^{\mathrm{b}} \pm 15,34$ & $179,30^{\mathrm{b}} \pm 23,17$ & $211,21^{\mathrm{d}} \pm 29,15$ & $240,67^{\mathrm{d}} \pm 32,09$ & $282,65^{\mathrm{d}} \pm 38,84$ \\
MT & $129,17^{\mathrm{a}} \pm 17,41$ & $186,85^{\mathrm{a}} \pm 25,19$ & $231,48^{\mathrm{b}} \pm 32,42$ & $269,88^{\mathrm{b}} \pm 37,79$ & $319,88^{\mathrm{b}} \pm 45,87$ \\
PA & $128,56^{\mathrm{a}} \pm 15,28$ & $187,62^{\mathrm{a}} \pm 21,93$ & $239,79^{\mathrm{a}} \pm 29,95$ & $274,00^{\mathrm{a}} \pm 36,21$ & $328,08^{\mathrm{a}} \pm 45,34$ \\
RO & $119,46^{\mathrm{c}} \pm 15,10$ & $169,31^{\mathrm{c}} \pm 20,67$ & $217,35^{\mathrm{c}} \pm 28,61$ & $242,19^{\mathrm{d}} \pm 31,90$ & $277,79^{\mathrm{e}} \pm 38,45$ \\
TO & $114,65^{\mathrm{d}} \pm 15,79$ & $164,49^{\mathrm{d}} \pm 23,19$ & $217,54^{\mathrm{c}} \pm 36,71$ & $252,64^{\mathrm{c}} \pm 41,92$ & $297,87^{\mathrm{c}} \pm 51,98$ \\
\hline
\end{tabular}

MA=Maranhão; MT= Mato Grosso; $\mathrm{PA}=$ Pará; $\mathrm{RO}=$ Rondônia; $\mathrm{TO}=$ Tocantins; $\mathrm{P} 120=$ Peso ajustado aos 120 dias de idade; $\mathrm{P} 210=$ Peso ajustado aos 210 dias de idade; P365= Peso ajustado aos 365 dias de idade; $\mathrm{P} 450=$ Peso ajustado aos 450 dias de idade; $\mathrm{P} 550=$ Peso ajustado aos 550 dias de idade; letras diferentes na mesma coluna significativamente diferentes $(\mathrm{p}<0,05)$ pelo teste de Tukey.

As médias fenotipicas para os diferentes pesos calculados (P120, P210, P365, P450 e P550 dias) foram comparadas e diferenças estatisticamente significativas $(\mathrm{p}<0,01)$ para essas pesagens foram evidenciadas entre os Estados (Tabela 2). Os resultados demonstraram que, nas unidades federativas, a média fenotipica dos pesos pode estar influenciada pelas condições ambientais em cada região, uma vez que os pesos de cada característica estudada (P120, P210, P365, P450 e P550) diferiram entre os Estados.

As estimativas de herdabilidades diretas e respectivos erros-padrão, para a região do Trópico Úmido do Brasil, obtidas em análises unicaráter, foram de $0,37( \pm 0,019) ; 0,39( \pm 0,019) ; 0,41( \pm$ $0,013) ; 0,41( \pm 0,015)$ e $0,41( \pm 0,021)$ para $\mathrm{P} 120$, $\mathrm{P} 210$, P365, P450 e P550 dias de idade, respectivamente. $\mathrm{E}$ os coeficientes de herdabilidades maternais para as características P120 e P210 foram $0,05( \pm 0,011)$ e $0,06( \pm 0,011)$, respectivamente.

As herdabilidades diretas estimadas para pesos pré-desmama foram de magnitude moderada, estando semelhante aos valores descritos por CÂMPELO et al. (2004) e SANTOS et al. (2012), e superiores aos encontrados por MERCADANTE et al. (2004), BOLIGON et al. (2007) e BOLIGON et al. (2008). LIRA et al. (2008), em revisão, relataram estimativas médias de herdabilidade direta de 0,08 e 0,64 para peso ao 120 dias e peso aos 205 dias de idade, respectivamente. No entanto, estão abaixo dos resultados descritos por CYRILLO et al. (2004) que relataram herdabilidades de 0,44 a 0,68 , na mesma ordem, para pesos aos 120 dias e 210 dias de idade.

$\mathrm{Na}$ avaliação das herdabilidades diretas estimadas para pesos pré-desmama (P120 e P210) nos estados do Maranhão, Mato Grosso, Pará, Rondônia e Tocantins, observou-se (Tabela 3) que a variabilidade entre os Estados é grande, variando de 0,22 a 0,61 para P120, e de 0,30 a 0,57 para P210. O Estado com menor herdabilidade para P120 e 210 foi Rondônia $(0,22$ e 0,30 na mesma ordem) e o de maior herdabilidade para os mesmos pesos foi $o$ Estado do Tocantins. A alta variabilidade encontrada nos Estados do Maranhão e Tocantins, pode estar 
relacionada à maior pressão de seleção das fêmeas (matrizes) para habilidade materna, uma vez que nesses estados os rebanhos são relativamente novos no programa de melhoramento e estão em processo de formação. Outro fator relacionado pode ser a repetibilidade de vacas $\left(\mathrm{c}^{2}\right)$, indicada pelo efeito de ambiente permanente comum entre estas, que foi de $65 \%$ e $25 \%$ nos estados do Tocantins e Maranhão, respectivamente.

No entanto, na região do Trópico Úmido do Brasil, a herdabilidade $\left(\mathrm{h}^{2}\right)$ materna para as características P120 e P210 mostraram-se de baixa magnitude $\quad(0,05 \pm 0,011$ e $0,06 \pm 0,011$, respectivamente), demonstrando pouca influência genética e ambiental da vaca sobre o desempenho dos indivíduos no pré-desmame. Esse resultado era esperado, uma vez o efeito de ambiente comum das vacas $\left(c^{2}\right)$, para P120 e P210, foram semelhantes
$(10,5 \%)$

Para as características pós-desmama (P365, P450 e P550) as herdabilidades diretas estimadas foram de alta magnitude, e apresentaram-se como de magnitudes semelhantes entre as unidades federativas (Tabela 3). Embora haja possibilidade de seleção para as características analisadas, isso demonstra que a pressão de seleção exercida na região para as características (P365, P450 e P550) é igual. Em geral, as estimativas de herdabilidade obtidas para pesos em diferentes idades neste estudo indicam que parte considerável da variação entre os animais, para essas características, é decorrente das diferenças no mérito genético dos animais, desse modo, parece haver concordância entre as unidades para maior pressão de seleção para pesos pósdesmama.

Tabela 3. Estimativas de (co)variâncias e parâmetros genéticos para as características de pré- e pósdesmama, segundo a unidade federativa

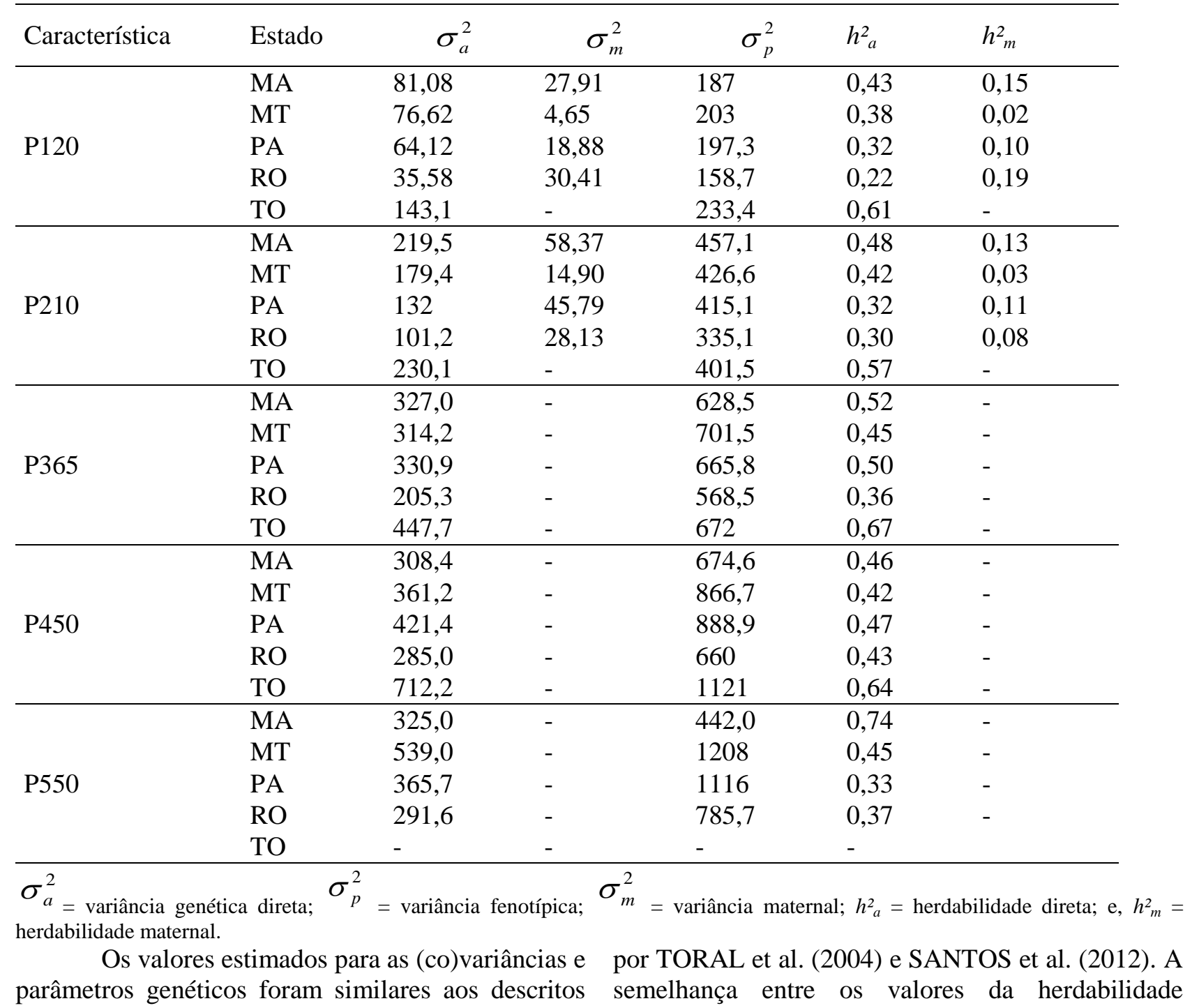


estimada para P365, P450 e P550 implica dizer que os genes que controlam estes pesos contribuíram de forma igual para a variância fenotípica e variância direta. Assim, esses valores são decorrentes da existência de variabilidade genética no rebanho e não apenas da influência do ambiente nessas características.

De um modo geral, as herdabilidades para as características pós-desmama (P365, P450 e P550) nas diferentes unidades federativas apresentaram alta magnitude, demonstrando possibilidade de seleção.
Resultados similares foram reportados por SANTOS et al. (2012), que analisaram dados da região Norte do Brasil e obtiveram estimativas de herdabilidades para pesos aos 365 e 550 dias de idade, da ordem de 0,41 a 0,51 , respectivamente.

A tendência genética dos pesos pré-desmama (Figura 1, A e B) no Trópico Úmido do Brasil revelaram seleção de animais com desempenho genotípico superior ao longo dos anos. A Figura 1 (A e B) mostra que não se tem feito seleção para habilidade maternal e sim para pesos.

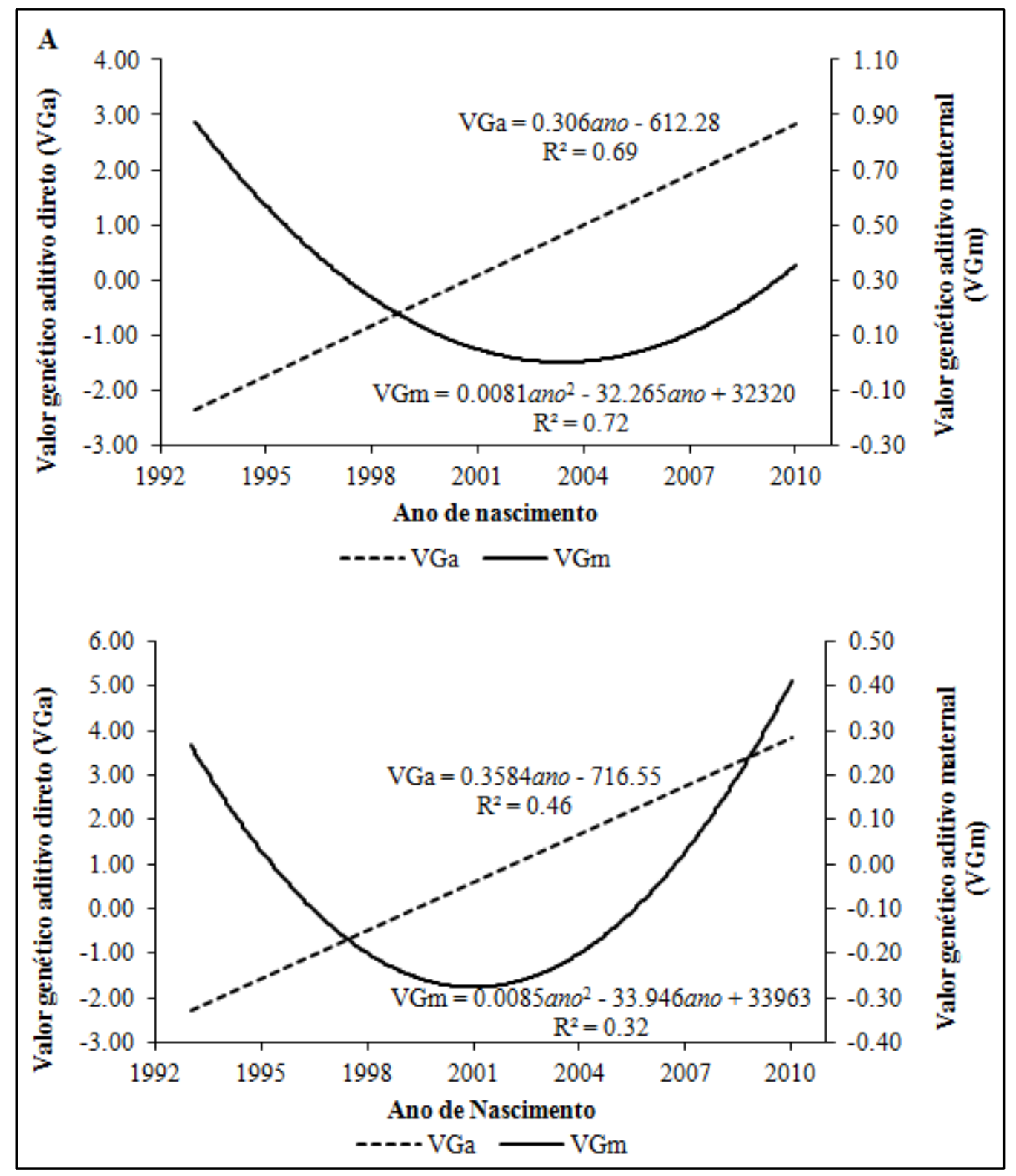

Figura 1. Tendências genéticas para peso padronizado aos 120 dias de idade (A) e peso padronizado aos 210 dias de idade (B), em bovinos criados na região do Trópico Úmido do Brasil.

Para P120 e P210, observou-se valor respectivamente. Com base nestes valores genéticos genético médio de 0,242 e $0,784 \mathrm{~kg} / \mathrm{ano}$, e nas estimativas de herdabilidade direta e desvio- 
padrão fenotípico (FALCONER, 1960; PEREIRA, 1999), foi realizada uma simulação, considerando-se uma retenção de $50 \%$ das fêmeas e $10 \%$ dos machos (intensidade de seleção de 1,28) e um intervalo médio de geração de cinco anos. Dessa forma, foi possível predizer ganhos genéticos de 1,33 e 2,01 $\mathrm{kg} / \mathrm{ano}$, o que representaria incrementos de $1,04 \%$ e $1,09 \%$ nos pesos calculados aos 120 e 210 dias de idade, respectivamente. Já para P365, P450 e P550 o valor genético aditivo direto médio foi de 3,136; 3,190 e 3,351 kg/ano, respectivamente. Considerando as informações da simulação anterior, foi possível predizer ganhos genéticos de 2,67, 3,05 e $3,13 \mathrm{~kg} / \mathrm{ano}$, o que representaria incrementos de $1,15 \%, 1,14 \%$ e $0,99 \%$ nos pesos calculados aos 365 , 450 e 550 dias de idade, respectivamente.

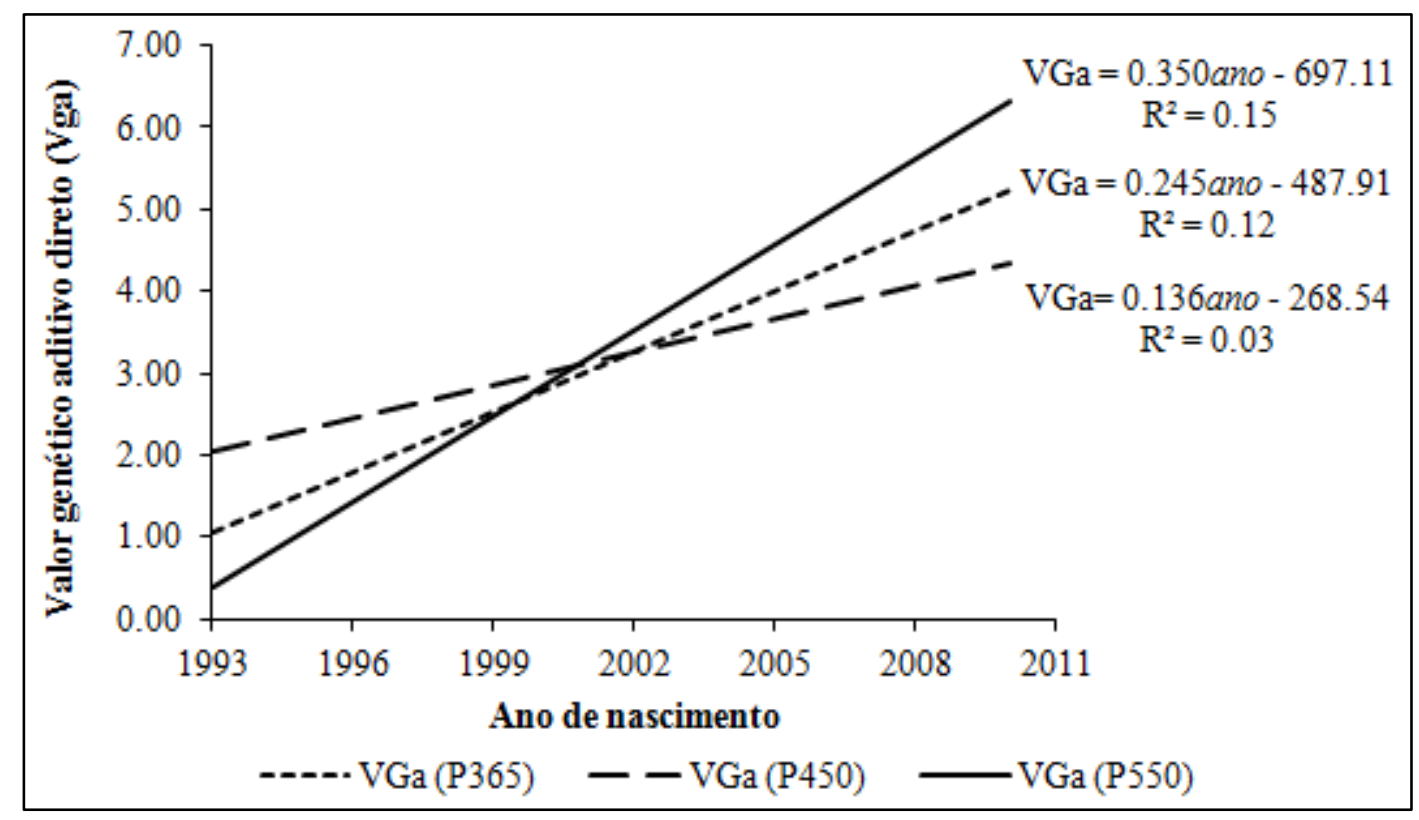

Figura 2. Tendências genéticas para peso padronizado aos 365, 450 e 550 dias de idade de bovinos da raça rebanhos Nelore criados na região do Trópico Úmido do Brasil.

As análises das tendências para os efeitos genéticos aditivos diretos para P120, P210, P365, P450 e P550 permitiram deduzir que a seleção do rebanho na região do Trópico Úmido do Brasil tem enfatizado principalmente os pesos após o desmame, corroborado pelas relações entre os valores genéticos e os valores fenotípicos, cujos valores genotípicos apresentaram percentuais de $0,19 \%, 0,42 \%, 1,36 \%$, $1,19 \%$ e $1,06 \%$ em relação aos seus respectivos pesos padrão para pesos aos $120,210,365,450$ e 550 dias de idade, respectivamente. Em outras palavras, para os pesos pós-desmame, os efeitos genéticos têm contribuído em mais de $1 \%$ do fenótipo dos animais, enquanto que para pesos prédesmame, esse mesmo efeito não passou de $0,5 \%$.

Ressalta-se que a seleção para pesos pósdesmame pode gerar, ao longo dos anos, aumento nos custos de produção, da idade ao abate e acabamento dos animais. Nesse sentido, sugere-se maior atenção e seleção de animais com maior potencial para pesos pré-desmame, pois é o período de vida no qual o animal apresenta maior velocidade de crescimento e desenvolvimento. Assim, com a seleção de animais para maiores pesos aos desmame seria possível reduzir o tempo para que o animal chegue ao peso ideal no momento do abate, reduzindo os custos de produção e a idade de abate dos animais.

\section{CONCLUSÕES}

As estimativas de herdabilidade, por apresentarem magnitudes de moderadas a altas, indicam a existência de variação genética aditiva suficiente para permitir ganhos genéticos por meio da seleção para as características em estudo. Ao longo dos anos, foram observados incrementos positivos para todas as características avaliadas. Face à tendência quadrática para o efeito maternal, sugerese maior atenção e seleção de fêmeas com melhor habilidade materna. De modo geral, os ganhos genéticos preditos evidenciaram a possibilidade de melhoras das características produtivas, principalmente os pesos padronizados aos $365,450 \mathrm{e}$ 
550 dias de idade.

\section{REFERENCIAS}

BERTAZZO, R.P.; FREITAS, R.T.F.; GONÇALVES, T.M.; PEREIRA, I.G.; ELER, J.P.; FERRAZ, J.B.S.; OLIVEIRA， A.I.G.; ANDRADE， I.F. Parâmetros genéticos de longevidade e produtividade de fêmeas da raça Nelore. Revista Brasileira de Zootecnia, v.33, n.5, p.1118-1127, 2004.

BOLDMAN, K.G., KRIESE, L.A., VAN VLECK, L.D. 1995. A manual for use of MTDFREML. A set of programs to obtain estimates of variance and covariances [DRAFT]. Lincoln: Department of Agriculture/Agricultural Research Service. 120p.

BOLIGON, A.A.; ALBUQUERQUE, L.G.; RORATO, P.R.N. Associações genéticas entre pesos e características reprodutivas em rebanhos da raça Nelore. Revista Brasileira de Zootecnia., v.37, p.596-601, 2008.

BOLIGON, A.A.; RORATO, P.R.N.; ALBUQUERQUE, L.G. Correlações genéticas entre medidas de perímetro escrotal e características produtivas e reprodutivas de fêmeas da raça Nelore. Revista Brasileira de Zootecnia, v.36, p.565-571, 2007.

CAMPÊLO, J. E. G.; LOPES, P. S.; TORRES, R. A.; SILVA, L. O. C.; EUCLYDES, R. F.; ARAÚJO, C. V.; PEREIRA, C. S. Maternal effects on the genetic evaluation of Tabapuã beef cattle. Genetics and Molecular Biology, v. 27, n. 4, p. 517-521, 2004.

CAMPÊLO, J. E. G.; $\quad$ LOPES, P. S.; TORRES, R. A.; SILVA, L. O. C.; EUCLYDES, R. F.; ARAÚJO, C. V.; PEREIRA, C. S. Infuência da heterogeneidade de variâncias na avaliação genética de bovinos de corte da Tabapuã. Arquivo Brasileiro de Medicina Veterinária e Zootecnia, v. 55, n. 6, p. 685-693, 2003.

CYRILLO, J.N.S.G.; RAZZOK, A.G.; FIGUEIREDO, L.A.; BONILHA NETO, L.M.; MERCADANTE, M.E.Z.; TONHATI, H. Estimativas de tendências e parâmetros genéticos do peso padronizados aos 378 dias de idade, medidas corporais e perímetro escrotal de machos Nelore de Sertãzinho, SP. Revista Brasileira de Zootecnia, v.30, p.56-65, 2001.

DIAS FILHO, M.B.; ANDRADE, C.M.S. Pastagens no Trópico Úmido. Belém, Pará: Embrapa Amazônia Oriental, 2006. 31p. (Série Documentos, N²41).

FALCONER, D.S. Introduction to quantitative genetics. 1 ed. The Ronald Press Company: New York, 1960, 365p.

GONÇALVES, F.M.; PIRES, A.V.; PEREIRA, I.G.; GARCIA, D.A.; FARAH, M.M.; MEIRA, C.T.; CRUZ, V.A.R. Avaliação genética para peso corporal em um rebanho Nelore. Arquivo Brasileiro de Medicina Veterinária e Zootecnia, v.63, n.1, p.594-598, 2011.

GUSMÃO, F.B., MALHADO, C.H.M., CARNEIRO, P.L.S., MARTINS FILHO, R. Tendências genéticas, fenotípicas e ambientais para D160 e D240 em bovinos nelore no estado da Bahia. Revista Ciência Agronômica, v.40, n. 2, p.301-305, 2009.

IBGE - Instituto Brasileiro de Geografia e Estatística. Produção da Pecuária Municipal, Rio de Janeiro, v. 35, p.1-62, 2007. Disponível em: < http://www.ibge.gov.br/home/estatistica/economia/ppm/2 007/ppm2007.pdf $>$.

IBGE - Instituto Brasileiro de Geografia e Estatística. Produção da Pecuária Municipal, Rio de Janeiro, v. 38, p.1-65, 2010. Disponível em: < http://www.ibge.gov.br/home/estatistica/economia/ppm/2 010/ppm2010.pdf>.

LAUREANO, M.M.M.; BOLIGON, A.A.; COSTA, R.B.; FORNI, S.; SEVERO, J.L.P.; ALBUQUERQUE, L.G. Estimativas de herdabilidade e tendências genéticas para características de crescimento e reprodutivas em bovinos da raça Nelore. Arquivo Brasileiro de Medicina Veterinária e Zootecnia, v.63, n.1, p.949-958, 2011.

LIRA, T.; ROSA, E.M.; GARNERO, A.V. Parâmetros genéticos de características produtivas e reprodutivas em zebuínos de corte (revisão). Ciência Animal Brasileira, v.9, n.1, p.1-22, 2008.

LÔBO, R. N. B. Genetic parameters for reproductive traits of Zebu cows in the semiarid region of Brazil. Livestock Production Science, v. 55, p. 245-248, 1998.

MALHADO, C.H.M.; FILHO, R.M.; LÔBO, R.N.B.; FACÓ, O.; AZEVEDO, D.M.M.R.; SOUZA, J.C.; OLIVEIRA, S.M.P. Tendências Genéticas para Características Relacionadas à Velocidade de Crescimento em Bovinos Nelore na Região Nordeste do Brasil. Revista Brasileira de Zootecnia, v.34, n.1, p.60-65, 2005.

MALHADO, C.H.M.; SOUZA, J.C.; SILVA, L.O.C.; FERRAZ FILHO, P.B. Correlações genéticas, fenotípicas e de ambiente entre os pesos de varias idades em bovinos da raça Guzerá no Estado de São Paulo. Archives of Veterinary Science, v.7, n.1, p.71-75, 2002.

MERCADANTE, M.E.Z.; PACKER, I.U.; RAZOOK, A.G.; CYRILLO, J.N.; FIGUEIREDO, L.A. Direct and correlated responses to selection for yearling weight on reprodutive performance of Nelore cows. Journal of Animal Science, v.81, p.376-384, 2003.

PEREIRA, J.C.C. Melhoramento genético aplicado à produção animal. 1 ed. FEP-MVZ Editora: Belo Horizonte, 1999. 493p.

PIMENTA FILHO, E.C.; MARTINS, G.A.; SARMENTO, J.L.R.; RIBEIRO,M.N.; MARTINS FILHO, R. Estimativas de herdabilidade de efeitos direto e materno de características de crescimento de bovinos Guzerá, no estado da Paraíba. Revista Brasileira de Zootecnia, v. 30, n. 4, p.1220-1223, 2001.

PLASSE, D.; VERDE, O.; FOSSI, H.; ROMERO, R.; HOOGESTEIJN, R.; BASTIDAS, P.; BASTARDO, J. (Co)variance components genetic parameters and animal trends for calf weigths in pedigree Brahman herd under selection for three decades. Journal Animal Breeding 
Genetics, v.119, p.141-153, 2002.

SANTOS, G. C. J; LOPES, F. B.; MARQUES, E. G; SILVA, M. C; CAVALCANTE, T.V; FERREIRA, J. L.

Tendência genética para pesos padronizados aos 205, 365 e 550 dias de idade de bovinos nelore da região Norte do Brasil. Acta Scientiarum. Animal Sciences, v. 34, p. 97$101,2012$.

SAS INSTITUTE. Statistical Analysis System: user guide. Version 8. Cary, 2002.
SMITH, C. Rates of genetic change in farm livestock. Research and Development in Agriculture, v.1, n.2, p.79-85, 1985 .

TORAL, F.L.B.; SILVA, L.O.C.; MARTINS, E.N.; GONODO, A.; SIMONELLI, S.M. Interação genótipoambiente em características de crescimento de bovinos da raça Nelore no Mato Grosso do Sul. Revista Brasileira de Zootecnia, v.33, n.6, p.1445-1455, 2004.

Protocolado em: 04 jan. 2012. Aceito em: 23 nov. 2012. 